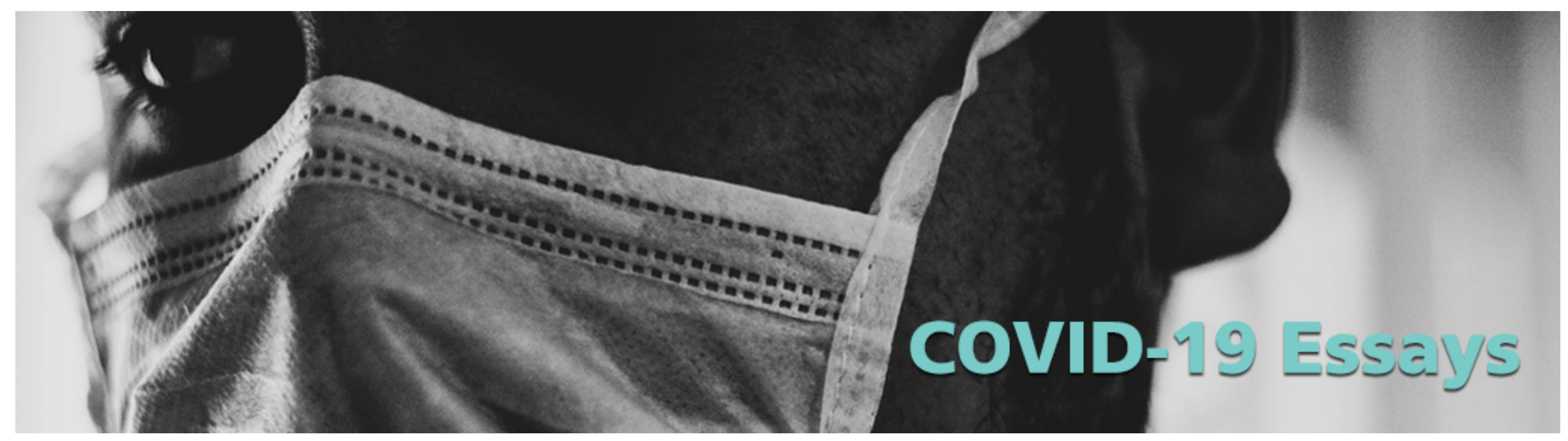

\section{Being in Common at a Distance}

\section{By: Elettra Stimilli}

DOI: 10.3138/topia.2020.covid-19.01

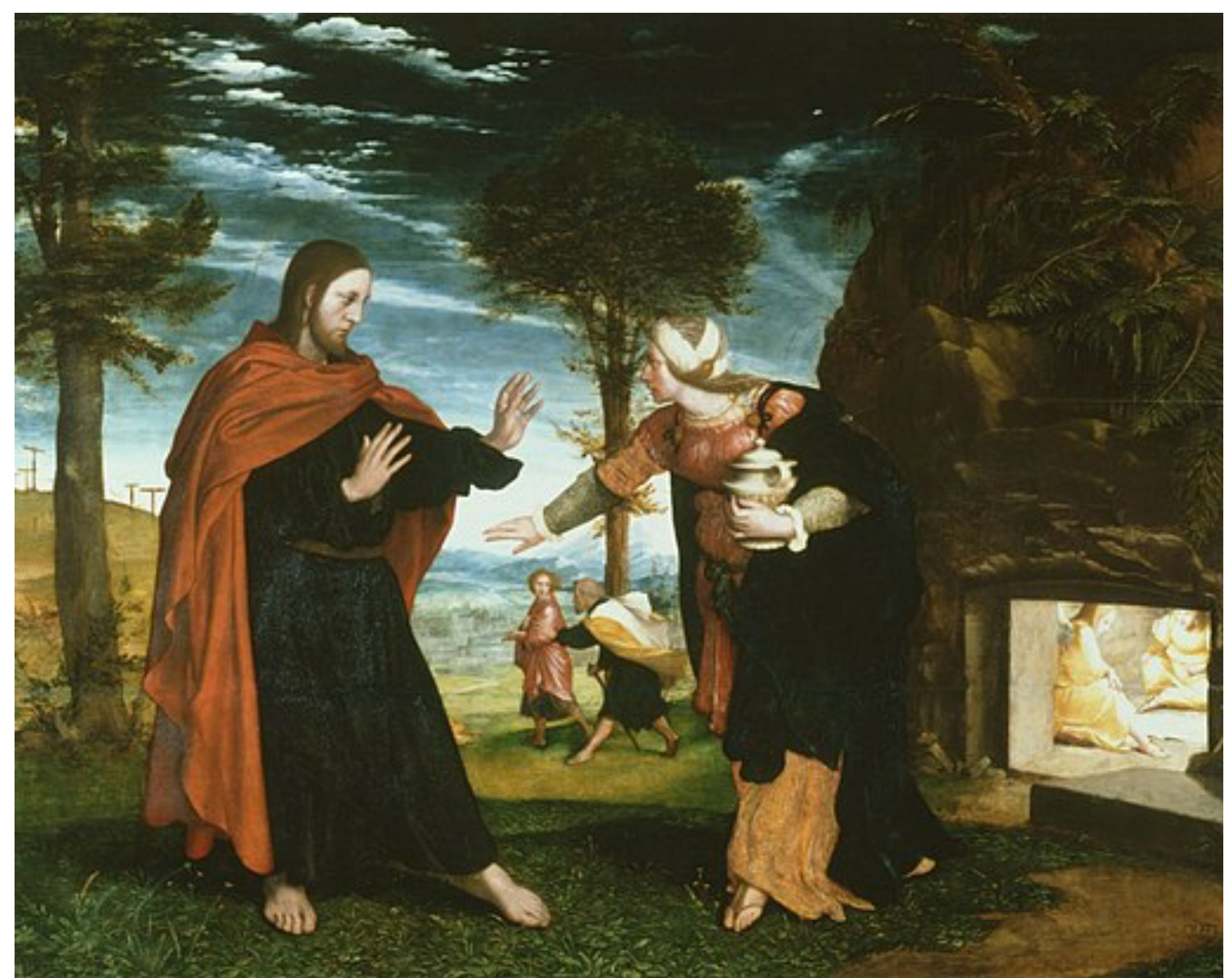

Noli Me Tangere, Hans Holbein (between 1532 and 1533). Wikimedia Commons (Royal Collection of the United Kingdom).

We err. In search of errors, we err again, repeatedly and without ends. Lost in the face of powerful invisible enemy. But is it an enemy? And how can we go
Connect with the Journal

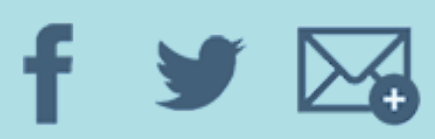

\section{DON'T MISS OUT!}

\section{Other Essays:}

\section{Being in Common at a Distance by Elettra Stimilli}

2. In the Distance by Philippe Theophanidis

3. Biopolitical Economies of the COVID-19 Pandemic by Jon Short 
4. On Ways of Living in the Midst of

How do I find the right words?

Decree upon decree endlessly issued in an effort to contain a situation from ever becoming more serious and more urgent. Declaring a state of emergency for a condition that is outside of ordinary laws. Decrees to contain what appears completely beyond control.

Are you trying to control even the most minute details? Because details are important... Just as some believe that the good Lord is hidden in the details.

One thing is certain now. What we thought we knew is no longer sufficient. What we believed to have understood will not provide an adequate analysis. We need new words...

Is vulnerable life bare? Are the bare lives of the habitants on this planet in turmoil? ${ }^{1}$

We live our bodies as objects of anguish, stripped bare when confronted by their exceptional significance. Bodies are not only vectors of epidemics, but also the means of transmitting what we are, means of communication. Symptoms of our common being, contours of sensitive and exposed epidermis, tasked with protecting and granting us contact. Possible forms, different from what we have inhaled, learned, memorized, forgotten, dreamed... Never just singular-an impossibility-but always in common.

Common that is never amassed, a compound, con-fusion. Never unified. Certainly not when you finally grasp its potentiality. Separation and distance are its custodians. Custodians of relations that are not feared, precisely because they are put to the test.

It is pointless to hypothesize forms of life without relations, to theorize life without relationships.

It is pointless to blame the theory when someone stumbles. Abstraction is always real. It is one of the most sublime forms the body assumes, which it needs.

Being in common at a distance is the practice that makes it possible to invent new words, new positions, new horizons. It instills something that is already occurring. But it is a practice which requires much patience.

A practice that countless women have experienced on their skin over the centuries, in their homes.

We will rediscover the centrality of the domestic condition. We have the opportunity to finally uncover the neglected political potentiality of a private sphere that does not deprive. If we were to care and pay close attention to the bodies that we use, which we thought we understood, they could carry us to previously unimaginable places.

This is an opportunity. We should not let it pass.

Elettra Stimilli (originally published on March 9, 2020

-https://antinomie.it/index.php/2020/03/09/essere-in-comune-adistanza/)

Translated on Friday, March 20, 2020 by Greg Bird (with special thanks to Roberta Buiani and John Paul Ricco). the COVID-19 Global Pandemic

(Three Brief Meditations) by John

Paul Ricco

5. Crisis, Critique, and the Limits of What We Can Hear by Stuart J. Murray
6. The Pandemic is (Extra) Ordinary
by Penelope Ironstone

\section{The Biopolitics of Numbers by Victor Li}

\section{Uncanny Convergences: Mobility and Containment in the Time of Coronavirus by Roberta Buiani}

\section{Biomedical Apparatuses or Conviviality? by Greg Bird}

10. Government-in-a-Box, or Understanding Pandemic Measures as Biopolitics by Neil Balan

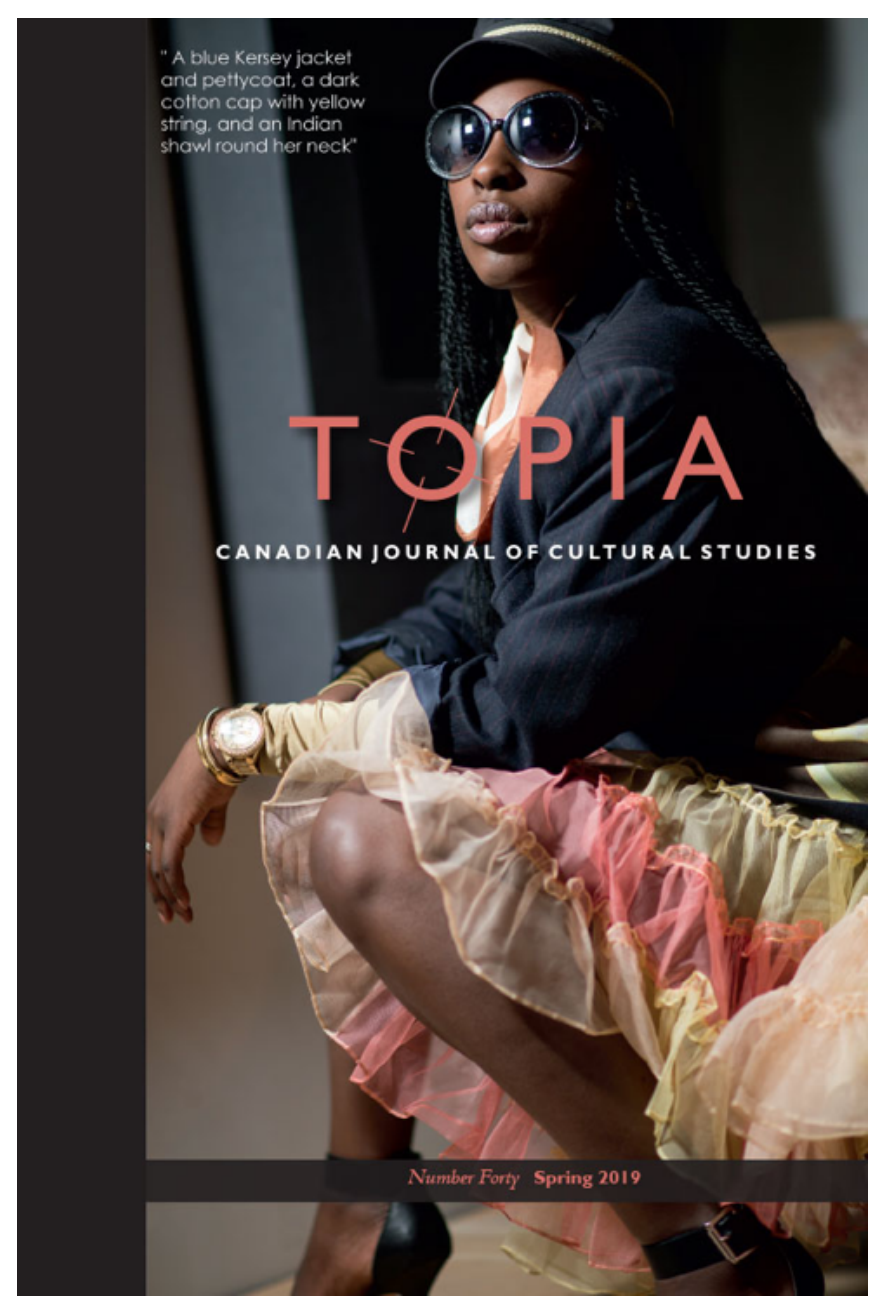

Share this page:

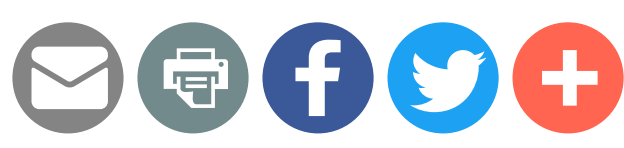

\section{Endnotes}

1 “Nuda è forse la vita colpita? Nude sono le vite degli abitanti di questo pianeta in 


\section{Author Bio}

Elettra Stimilli is Professor of Theoretical Philosophy at the Sapienza University of Rome. She authored numerous essays that revolve around the relationship between politics, economy and religion, focusing particularly on contemporary thought. Among others, she published "The Debt of the Living", SUNY Press, New York 2017, and "Debt and Guilt" Bloomsbury, London 2018.

I'm on Facebook and twitter (@E_Stimilli).

The UTP Journals collection features guest posts from our authors. The opinions expressed in these posts may not necessarily represent those of UTP Journals and their clients.

\section{UNIVERSITY OF TORONTO PRESS}

Journals Division

\section{ABOUT}

UTP Journals

List of Journals

Copyright \& Permissions

Publication Ethics \& Malpractice

Open Access

Publish with Us

Contact Us

\section{RESOURCES}

Resource Centre

FAQ

Authors

Librarians

Subscribers

Site Help

Site License Agreement (PDF)

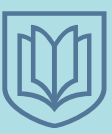

UTP

UTP Books Job Opportunities Environmental Policy Privacy Policy

Accessibility Policy 